\title{
A ADERÊNCIA DAS NORMAS DO MERCADO DE SEGUROS À DIRETIVA DE SOLVÊNCIA II E SUA EFETIVIDADE
}

Reinaldo Santos Barros ${ }^{1}$

\section{RESUMO}

Este artigo apresenta um breve histórico do desenvolvimento das Normas Internacionais de Solvência e as principais diretivas de Solvência II. Com foco no mercado de Seguros de Danos, demonstra o alinhamento do respectivo arcabouço regulatório nacional com os princípios aceitos internacionalmente. Apresenta ainda uma reflexão sobre a efetividade das Normas Brasileiras e considerações finais.

Palavras-chave: Seguros; Regulação; Normas; Solvência; Mercado financeiro.

\section{INTRODUÇÃO}

Em junho de 1999, o Comitê de Basileia de Supervisão Bancária (Basel Committee on Banking Supervision) publicou um relatório de enquadramento sobre um novo acordo de capital (BIS, 1999), o primeiro documento consultivo (CP1). O novo quadro consiste em três pilares:

1. Exigência de capital mínimo.

2. Processo de revisão de supervisão.

Professor da UFRJ. 
•• Economia Brasileira em Debate

3. Utilização eficaz da disciplina de mercado.

\begin{tabular}{|c|c|c|}
\hline \multicolumn{2}{|c|}{ Basileia II - Estrutura Regulação Bancária } \\
\hline Pilar I: & Pilar II: & Pilar III: \\
Capital Mínimo Requerido & Procedimento de Supervisão & Disciplina de Mercado \\
\hline
\end{tabular}

$\mathrm{Na}$ construção do novo quadro de capital, é importante continuar a reconhecer o Capital Mínimo Requerido (regulatório), que é o primeiro pilar. O segundo pilar é a adequação de capital e o processo de avaliação interna de uma instituição financeira e o terceiro é a necessidade de uma maior disciplina de mercado².

Com relação, especificamente, ao mercado de seguros, essa estrutura é encontrada nos princípios que norteiam o Solvência II da União Europeia e nas recomendações da International Association of Insurance Supervisors (IAIS).

Considerando a participação do Brasil como membro da IAIS ${ }^{3}$, nosso objetivo será demonstrar a existência do esperado alinhamento dos princípios mais relevantes do arcabouço regulatório do mercado segurador brasileiro, com foco nos Seguros de Danos, às melhores práticas e regras internacionais, bem como algumas implicações práticas.

Este artigo tratará acerca dos Pilares I, II e III, nos itens 2, 3 e4, respectivamente. No item 5, discorreremos sobre a efetividade das Normas de Solvência e no item 6 , as considerações finais.

\section{O PILAR I}

O foco deste item $\mathbf{2}$ será o Pilar I, ou seja, os Requerimentos de Capital. Iniciaremos com uma breve abordagem sobre o projeto Solvência II (item 2.1), para, em seguida, destacar a aderência observada nas Normas Brasileiras em importantes dispositivos (item 2.2).

\subsection{O Pilar I de Solvência II}

A diretiva que regulamenta o projeto Solvência II (EUROPEAN PARLIAMENT AND THE COUNCIL OF THE EUROPEAN UNION, 2014) determina que

2 (Sandström, 2006, p. 59)

3 (Susep, 2012a) 
os Estados-Membros garantam que os elementos do Ativo sejam avaliados pelo montante por que podem ser transacionados entre partes informadas, agindo de livre vontade numa transação em condições normais de mercado, e os do passivo pelo montante por que podem ser transferidos ou liquidados.

A abordagem padrão para medir o valor econômico dos ativos e passivos é a marcação a mercado, com base em preços transacionados, provenientes de fontes independentes - preços de mercado cotados em mercados ativos, salvo no caso de impossibilidade, quando deve ser utilizada a marcação a modelo.

O valor das Provisóes Técnicas, por sua vez, deve corresponder ao montante atual que uma seguradora teria que pagar se transferisse imediatamente as suas obrigaçōes para outra empresa. Para tal, devem ser utilizadas informaçôes fornecidas pelos mercados financeiros, dados estatísticos das operações da companhia e premissas consistentes e coerentes, tanto em relação à companhia como em relação ao mercado.

As provisões devem ser calculadas com prudência, confiabilidade e objetividade e seu valor deve ser igual à soma da melhor estimativa e da margem de risco. Define-se melhor estimativa como a média dos fluxos de caixa futuros, ponderados pela sua probabilidade, tendo em conta o valor do dinheiro no tempo, utilizando a estrutura a termo das taxas de juros livre de risco, enquanto a margem de risco deve ser mensurada tal que garanta que o valor das provisões técnicas seja equivalente ao montante que as seguradoras deveriam normalmente exigir para assumir e cumprir as obrigações de seguro.

O Requerimento de Capital é o montante mínimo requerido pelo regulador para operar e, de acordo com o que prevê o IAIS, "o regime de solvência deve incluir um leque de níveis de controle de solvência que disparam diferentes graus de intervenções pelo supervisor de forma imediata”.

A figura a seguir ilustra esses três conceitos do balanço sob solvência II (Ativos, Provisões Técnicas e Requerimento de Capital $)^{4}$ :

4 (Melo \& Neves, 2012, p. 66) 
•• Economia Brasileira em Debate

Figura 1 Balanço sob Solvência II.

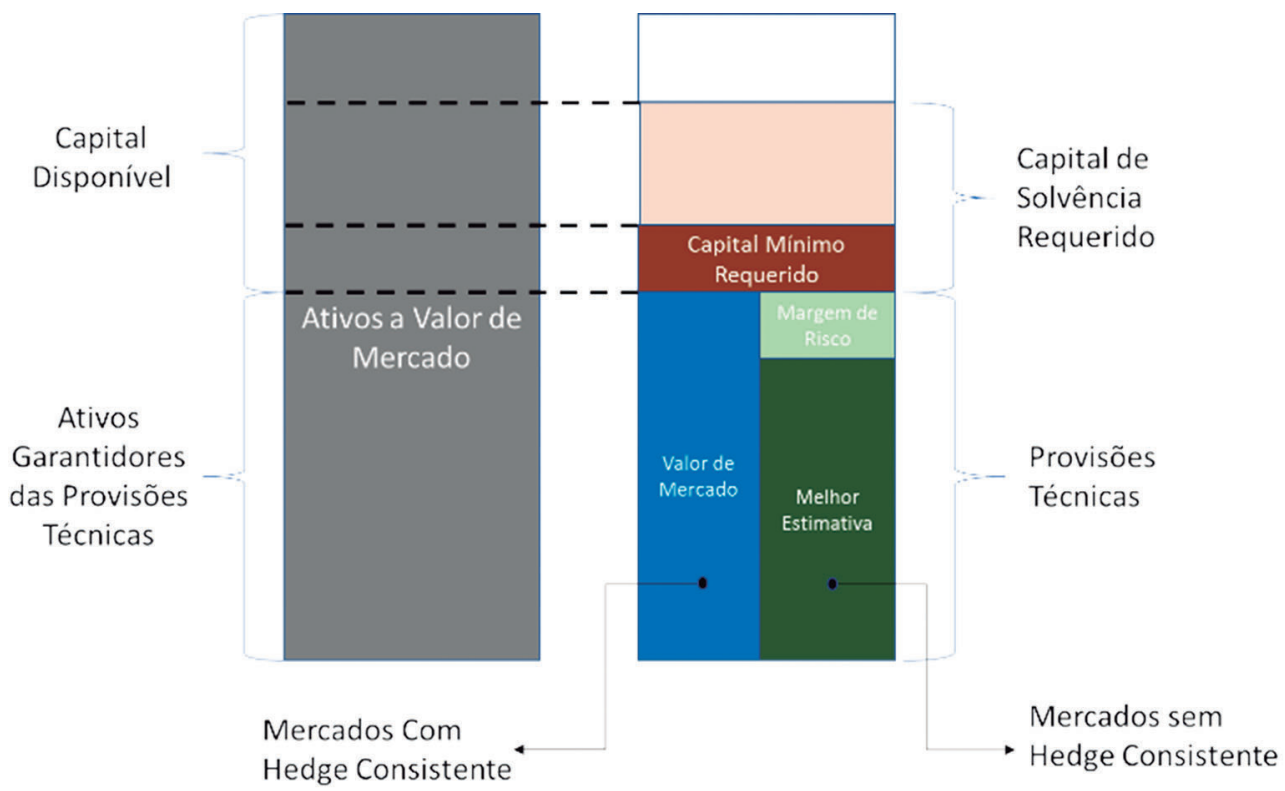

\subsection{Aderência das Normas Brasileiras - Pilar I}

Para demonstrar a aderência das Normas Brasileiras ao Pilar I de Solvência II, apresentaremos em 2.2.1 as abordagens referentes às Provisões Técnicas e, em 2.2.2 e 2.2.3, sobre os ativos aceitos para cobertura dessas Provisōes, enquanto em 2.2.4 trataremos sobre o Capital Mínimo Requerido e, em 2.2.5, os Ativos aceitos para fins de monitoramento do regulador. Em 2.2.6 apresentaremos uma comparação entre dispositivos voltados para absorção de volatilidade, enquanto em 2.2.7, apresentaremos uma síntese do arcabouço regulatório brasileiro no aspecto de Exigência de Capital.

\subsubsection{Provisões Técnicas}

Os dispositivos que tratam das Provisões Técnicas das Seguradoras no Brasil são a Resolução CNSP n. 321/2015 e a Circular Susep n. 517/15 e alteraçōes respectivas. Enquanto que o Capítulo I do Título I da Resolução CNSP n. 321/15 se baseia em princípios e em disposiçōes mais abrangentes, o Capítulo I do Título I da Circular Susep n. 517/15 trata de regras e procedimentos mais específicos. De uma forma abrangente, as sociedades seguradoras devem constituir as seguintes provisōes: 
- Provisão de Prêmios Não Ganhos (PPNG)

Deverá ser constituída para a cobertura dos valores a pagar relativos a sinistros e despesas a ocorrer. A fração referente aos riscos emitidos (PPNG-RVE) é calculada a partir de uma fórmula padrão definida na Circular Susep n. 517/2015 e a de vigentes e não emitidos (PPNG-RVNE), atuarialmente.

As Seguradoras que não dispõem de dados suficientes para utilização de metodologia própria devem constituir A PPNG-RVNE segundo o disposto na seção IV da Circular Susep n. 517/2015.

- Provisão de Sinistros a Liquidar (PSL)

Deverá ser constituída para a cobertura dos valores a liquidar relativos a sinistros avisados. Deverá contemplar, quando necessário, os ajustes de IBNeR (Sinistros Ocorridos e Não Suficientemente Avisados) para o desenvolvimento agregado dos sinistros avisados e ainda não pagos, cujos valores poderão ser alterados ao longo do processo até a sua liquidação final. A expectativa de Salvados e Ressarcimentos (respectivos aos sinistros constantes na PSL e que ainda não se encontrem ativados) deve ser apurada com base em metodologia própria.

- Provisão de Sinistros Ocorridos e Não Avisados (IBNR)

Deverá ser constituída para a cobertura dos valores a liquidar relativos a sinistros ocorridos e não avisados. A expectativa de salvados deve ser apurada com base em metodologia própria e registrado em conta específica. As Seguradoras que não dispõem de dados suficientes para utilização de metodologia própria devem constituir o IBNR segundo o disposto na seção IV da Circular Susep n. 517/2015.

- Provisão Matemática de Benefícios a Conceder (PMBAC)

Deverá ser constituída, enquanto não ocorrido o evento gerador do benefício, para a cobertura dos compromissos assumidos com os segurados.

- Provisão Matemática de Benefícios Concedidos (PMBC)

Deverá ser constituída, após ocorrido o evento gerador do benefício, para a cobertura dos compromissos assumidos com os participantes ou segurados.

- Provisão de Despesas Relacionadas (PDR)

Deverá ser constituída para a cobertura das despesas relacionadas a sinistros. 
- Provisão de Excedentes Técnicos (PET)

Deverá ser constituída para garantir os valores destinados à distribuição de excedentes decorrentes de superávit técnico na operacionalização de seus contratos.

- Provisão de Excedentes Financeiros (PEF)

Deverá ser constituída para garantir os valores destinados à distribuição de excedentes financeiros.

- Provisão de Resgates e Outros Valores a Regularizar (PVR)

Deve abranger outros valores a regularizar, tais como devoluções de prêmios.

- Outras Provisões Técnicas (OPT)

Somente poderá ser admitida mediante prévia autorização da Susep, devendo estar prevista em nota técnica atuarial assinada pelo atuário técnico responsável.

\section{- Provisão Complementar de Cobertura (PCC)}

Deverá ser constituída, quando for constatada insuficiência nas provisões técnicas, com base no valor apurado no Teste de Adequação de Passivos (TAP), que trataremos a seguir.

\subsubsection{O Teste de Adequação de Passivo (TAP) e o Alinhamento da PCC}

O TAP apareceu a primeira vez no arcabouço regulatório nacional na Circular Susep 410 de 22 de dezembro de 2010 e se apresentava como um importante alinhamento às Normas Internacionais, em especial o IFRS 4 (International Accounting Standards Board (IASB), 2009). A Circular n. 457 de 14 de dezembro de 2012 institui prazos para reconhecimento do TAP no balanço, 50\% em 30 de junho de 2013 e a totalidade em 31 de dezembro de 2013.

Observa-se que todas as obrigações do contrato são suportadas, sem considerar a PCC, pelo conjunto de Provisões Técnicas, assim na ausência de prática de taxas subdimensionadas (cuja consequência direta é a constituição insuficiente da PPNG para a cobertura dos valores a pagar relativos a sinistros e despesas a ocorrer) ou premissas inadequadas (que podem impactar a PMBAC ou PBC) ou de subprovisionamento das demais Provisões Técnicas, não haverá de ser constituída a PCC, uma vez que essa é destinada para quando for constatada insuficiência nas provisões técnicas, conforme valor apurado no Teste de Adequação de Passivos (TAP). 
Na prática, a PCC deve ser constituída para a cobertura de insuficiências relacionadas às provisões de PPNG, PMBAC e PMBC, as quais possuem regras de cálculos rígidas ${ }^{5}$, que não podem ser alteradas em decorrência de insuficiências. Os ajustes decorrentes de insuficiências nas demais provisões técnicas, apuradas no TAP, devem ser efetuados nas próprias provisões (Susep, 2017b).

Nesse caso, a companhia deverá recalcular o resultado do TAP com base nas provisões ajustadas, e registrar na PCC apenas a insuficiência remanescente. De acordo com o art. 45 da Circular Susep n. 517/15, as seguradoras deverão elaborar o Teste de Adequação de Passivos (TAP) para avaliar as obrigações decorrentes dos seus contratos, utilizando métodos estatísticos e atuariais com base em informações realistas. $\mathrm{O}$ art. 47 daquela Circular, a seguir transcrito, dispõe:

Art. 47. As estimativas correntes dos fluxos de caixa deverão considerar todos os riscos assumidos até a data-base do teste, sendo brutas de resseguro para as seguradoras e EAPC e de retrocessão para os resseguradores locais.

É possível observar a aderência desse ao dispositivo ao encontrado no IFRS 4 acerca do TAP (Liability Adequacy Test):

An insurer shall assess at the end of each reporting period whether its recognized insurance liabilities are adequate, using current estimates of future cash flows under its insurance contracts. If that assessment shows that the carrying amount of its insurance liabilities (less related deferred acquisition costs and related intangible assets, such as those discussed in paragraphs 31 and 32) is inadequate in the light of the estimated future cash flows, the entired efficiency shall be recognised in profit or loss.

\subsubsection{O alinhamento das demais provisões técnicas}

Com relação as demais provisões técnicas, nos últimos anos, houve duas alterações na Norma que se sobressaem no sentido de alinhar os Normativos às Normas Internacionais, quais sejam:

i) Provisão de Insuficiência de Prêmios - A Circular Susep n. 457/2012 passa a prever a utilização do resultado do TAP para sua constituição, que até então era calculada de forma, significativamente, mais simplória ${ }^{6}$. A PIP, posteriormente, foi substituída pela PCC.

Provisões Brutas de Resseguro: A partir da Resolução CNSP n. 195/2008, as Provisões Técnicas passaram a ser apresentadas brutas de Resseguro no Passivo,

5 Ver Circular Susep n. 517/2015.

6 Ver Resolução CNSP n. 162/2006 e alterações. 
enquanto os direitos das Seguradoras junto aos Resseguradores, no Ativo, alinhando-se a um Princípio Básico das Normas Internacionais com relação à transparência (que abordaremos no item -4 - Pilar III - Disciplina de Mercado), mas também de Requerimento de Capital, conforme disposto em Solvência II em Cálculo da Provisões Técnicas, a seguir transcrito:

"The Best estimate shall be calculated gross, without deduction of the amounts recoverable from reinsurance contracts."

ii) Provisão Complementar de Prêmios (PCP): Provisão que equivalia a diferença, se positiva, entre a média da soma dos valores apurados diariamente no mês de constituição e a PPNG constituída, considerando todos os riscos vigentes, emitidos ou não, sendo que, sob os normativos internacionais, a PCP não poderia ser considerada Provisão Técnica uma vez que não corresponde a uma obrigação das Seguradoras para com os segurados, contrariando, inclusive, o disposto em Solvência II e em, especificamente no encontrado no item 17.1.3 do ICP 17 - Adequação de Capital, a seguir transcrito:

"Technical provisions represent the amount that an insurer requires to fulfil its insurance obligations and settle all commitments to policy holders and other beneficiaries arising over the lifetime of the portfolio" (IAIS, 2015).

\subsubsection{Ativos garantidores de provisão técnica}

As Provisões Técnicas devem ser cobertas de acordo com a Legislação vigente, atualmente a Resolução CNSP N ${ }^{\circ}$ 321/2015, Circular Susep n. 517/2015 e, em especial, a Resolução CMN n. 4.444/2015 e alterações, uma vez que dispõem sobre as regras de aceitação de ativos como garantidores de Provisão Técnica (exemplo: sejam registrados em sistemas de registros, objeto de custódia ou objeto de depósito centralizado), bem como de não aceitação (exemplo: fundo de investimento cujas operações possam resultar Patrimônio Líquido negativo e/ou ações, títulos, valores mobiliários ou qualquer obrigação de emissão da própria sociedade seguradora ou parte relacionada e/ou títulos ou valores mobiliários de emissão ou coobrigação de pessoas físicas).

A Resolução CMN n. 4.444/2015 e alterações segmentamos ativos aceitos em cinco grandes grupos (previsto nos arts. $8^{\circ}, 9^{\circ}, 10,11$ e 12), que por sua vez são subdivididos (regulação constante nos incisos desses artigos), conforme exemplificado a seguir: 
Renda Fixa (Art. $8^{\circ}$ )

Inciso I - exemplo: Títulos da Dívida Pública Mobiliária Federal Interna

Inciso II - exemplo: valores mobiliários ou outros ativos financeiros de renda fixa emitidos por companhia aberta cuja oferta pública tenha sido registrada na Comissão de Valores Mobiliários, ou que tenha sido objeto de dispensa

Inciso III - exemplo: obrigações ou coobrigações de instituições financeiras autorizadas a funcionar pelo Banco Central do Brasil.

Inciso IV - exemplo: certificados de recebíveis de emissão de companhias securitizadoras, na forma regulamentada pela Comissão de Valores Mobiliários.

Renda Variável (Art. 9)

Inciso I - exemplo: ações de emissão de companhias abertas, correspondentes bônus de subscrição, recibos de subscrição e certificados de depósito, admitidas à negociação em segmento especial, instituído por bolsa de valores no Brasil, que assegurem, por meio de vínculo contratual entre a bolsa e o emissor, práticas diferenciadas de governança corporativa, que contemplem, pelo menos, a obrigatoriedade de no mínimo 25\% (vinte e cinco por cento) de ações permanentemente em circulação (freefloat) e previsão expressa no estatuto social da companhia de que seu capital social seja dividido exclusivamente em ações ordinárias

Inciso II - exemplo: ações de emissão de companhias abertas que permitam a existência de ações $\mathrm{ON}$ e PN (com direitos adicionais), correspondentes bônus de subscrição, recibos de subscrição e certificados de depósito, admitidas à negociação em segmento especial, instituído por bolsa de valores no Brasil, que contemplem previsão expressa no estatuto social da companhia de que o conselho de administração deve ser composto por no mínimo cinco membros, dos quais pelo menos $20 \%$ (vinte por cento) devem ser independentes com mandato unificado de até dois anos, conforme critério estabelecido pela bolsa de valores

Inciso III - exemplo: ações de emissão de companhias abertas cuja composição do Conselho de Administração possua um mínimo de três membros (conforme legislação), com mandato unificado de até dois anos, admitidas à negociação em segmento especial, instituído por bolsa de valores no Brasil e correspondentes bônus de subscrição, recibos de subscrição e certificados de depósito.

Inciso IV - exemplo: ações sem percentual mínimo em circulação (freefloat), correspondentes bônus de subscrição, recibos de subscrição e certificados de depósito, admitidas à negociação em bolsa de valores no Brasil. 


\section{1) Imóveis (Arts. 10 e 31)}

Podemos dizer que os imóveis se encontram segmentados em dois grupos, os imóveis propriamente ditos, que partir de 02/11/2017 imóveis não mais serão aceito (conforme disposto no Art. 31) e as cotas de fundos de investimento imobiliário (FII) e cotas de fundos de investimento em cotas de fundos de investimento com tais características (FICFII), sem restrição temporal para aceitação.

\section{2) Investimentos Sujeitos à Variação Cambial (Art. 11)}

Inciso I - exemplo: títulos da Dívida Pública Mobiliária Federal cuja remuneração seja associada à variação da cotação de moeda estrangeira

Inciso II - exemplo: certificados de depósito de valores mobiliários com lastro em ações de emissão de companhia aberta ou assemelhada com sede no exterior - Brazilian Depositary Receipts (BDR), negociados em bolsa de valores no País

Inciso III - títulos e valores mobiliários representativos de dívida corporativa de empresas brasileiras de capital aberto, emitidos e negociáveis no exterior.

Inciso IV - somatório dos seguintes títulos emitidos ou incondicionalmente garantidos por instituições financeiras no exterior em moeda estrangeira:

a) depósitos a prazo fixo por até seis meses, renováveis; e

b) certificados de depósitos.

\section{3) Outros}

\section{(Art. 12)}

Inciso I - exemplo: COE com Valor Nominal Protegido

Inciso II - cotas de Fundos de Investimento em Participações (FIP) e as cotas de fundos de investimento em cotas de fundos de investimento com tais características (FICFIP),

Inciso III - COE com Valor Nominal em Risco.

Inciso IV - somatório dos seguintes títulos emitidos ou incondicionalmente garantidos por instituições financeiras no exterior em moeda estrangeira:

a) depósitos a prazo fixo por até seis meses, renováveis; e

b) certificados de depósitos.

O limite para aplicação em cada um dos grupos definidos pelos artigos e incisos dispostos acima dependem da Provisão a ser coberta (art. 13), existindo a segmentação em quatro grupos, bastante correlacionado com o segmento de atuação, sendo o Seguro de Danos, via de regra, alcançado pelo inciso IV (exceto para operação em moeda estrangeira e crédito à exportação) de acordo com o a seguir demonstrado: 


\section{Art. 13 - Provisão a ser coberta}

Inciso I - aplicações de planos abertos de previdência complementar e de seguros de pessoas com cobertura por sobrevivência, cuja remuneração esteja calcada na rentabilidade de carteiras de investimentos durante o prazo de diferimento

Inciso II - aplicações de planos abertos de previdência complementar e de seguros de pessoas com cobertura por sobrevivência, cuja remuneração esteja calcada na rentabilidade de carteiras de investimentos durante o prazo de diferimento, destinados exclusivamente a Participantes Qualificados na forma definida pelo Conselho Nacional de Seguros Privados

Inciso III - aplicações das sociedades seguradoras e de resseguradores locais vinculadas às operações em moeda estrangeira e de seguros de crédito à exportação

Inciso IV-Demais

Nesta linha o limite de alocação em cada grupo (cada inciso dos arts. $8^{\circ}$ a 12 ) é dado pela multiplicação do limite máximo previsto no inciso específico dos artigos de $8^{\circ}$ a 12 pelo limite máximo previsto no art. 13, considerando a modalidade de investimento a qual o ativo pertença (Renda Fixa, Renda Variável, etc.) e o tipo de provisão ou segmento, conforme descrito em cada inciso do art. 13, tal como resumido no quadro a seguir (Susep, 2017e):

\begin{tabular}{|c|c|c|c|c|c|c|}
\hline LIMITES & \multicolumn{2}{|c|}{ Segmentos --> } & Art. 13, inciso I & Art. 13, inciso II & Art. 13, inciso III & Art. 13, inciso IV \\
\hline \multirow{22}{*}{ 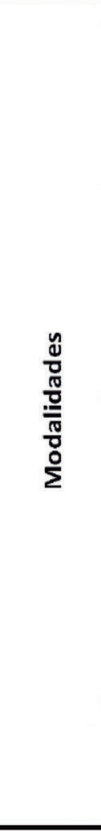 } & \multicolumn{2}{|l|}{ Renda Fixa } & $100 \%$ & $100 \%$ & $100 \%$ & $100 \%$ \\
\hline & Art. $8 \%$, incisol & $100 \%$ & $100,0 \%$ & $100,0 \%$ & $100,0 \%$ & $100,0 \%$ \\
\hline & Art. 8 , inciso II & $75 \%$ & $75,0 \%$ & $75,0 \%$ & $75,0 \%$ & $75,0 \%$ \\
\hline & Art. 89, inciso III & $50 \%$ & $50,0 \%$ & $50,0 \%$ & $50,0 \%$ & $50,0 \%$ \\
\hline & Art. 80 , inciso IV & $25 \%$ & $25,0 \%$ & $25,0 \%$ & $25,0 \%$ & $25,0 \%$ \\
\hline & \multicolumn{2}{|l|}{ Renda Variável } & $70 \%$ & $100 \%$ & $49 \%$ & $49 \%$ \\
\hline & Art. 99, incisol & $100 \%$ & $70,0 \%$ & $100,0 \%$ & $49,0 \%$ & $49,0 \%$ \\
\hline & Art. 9o, inciso II & $75 \%$ & $52,5 \%$ & $75,0 \%$ & $36,8 \%$ & $36,8 \%$ \\
\hline & Art. 99, inciso III & $50 \%$ & $35,0 \%$ & $50,0 \%$ & $24,5 \%$ & $24,5 \%$ \\
\hline & Art. 99, inciso IV & $25 \%$ & $17,5 \%$ & $25,0 \%$ & $12,3 \%$ & $12,3 \%$ \\
\hline & \multicolumn{2}{|l|}{ Imóveis } & $20 \%$ & $40 \%$ & $20 \%$ & $20 \%$ \\
\hline & Art. 10 & $100 \%$ & $20,0 \%$ & $40,0 \%$ & $20,0 \%$ & $20,0 \%$ \\
\hline & \multicolumn{2}{|l|}{ Art. $31^{*}$} & & & & $8,0 \%$ \\
\hline & \multicolumn{2}{|c|}{ Invest. Suj. à Var. Cambial } & $10 \%$ & $10 \%$ & $100 \%$ & $10 \%$ \\
\hline & Art. 11, inciso I & $100 \%$ & $10,0 \%$ & $10,0 \%$ & $100,0 \%$ & $10,0 \%$ \\
\hline & Art. 11, inciso II & $75 \%$ & $7,5 \%$ & $7,5 \%$ & $75,0 \%$ & $7,5 \%$ \\
\hline & Art. 11, inciso III & $50 \%$ & $5,0 \%$ & $5,0 \%$ & $50,0 \%$ & $5,0 \%$ \\
\hline & Art. 11, inciso IV & $25 \%$ & $2,5 \%$ & $2,5 \%$ & $25,0 \%$ & $2,5 \%$ \\
\hline & \multicolumn{2}{|l|}{ Outros } & $20 \%$ & $40 \%$ & $20 \%$ & $20 \%$ \\
\hline & Art. 12, inciso I & $100 \%$ & $20,0 \%$ & $40,0 \%$ & $20,0 \%$ & $20,0 \%$ \\
\hline & Art. 12, inciso II & $75 \%$ & $15,0 \%$ & $30,0 \%$ & $15,0 \%$ & $15,0 \%$ \\
\hline & Art. 12, inciso III & $25 \%$ & $5,0 \%$ & $10,0 \%$ & $5,0 \%$ & $5,0 \%$ \\
\hline
\end{tabular}

*Imóveis serão aceitos até 02/11/2017 (inclusive), cf. Res. CMN 4.444/15 e respeitando os limites previstos no Art. 11 da Res. CMN 3.308/05. 
Não obstante aos limites de alocação em cada grupo, a Resolução CMN 4.444 define, ainda, limites de alocação por emissor, limite de concentração por emissor, limite de alocação por investimento. Esse conjunto de limitações para alocação está alinhado com os princípios de Markowitz, de 1952, acerca da diversificação ${ }^{7}$, até os mais atuais da IAIS $^{8}$, que na abordagem dos Princípios Fundamentais de Seguro (Insurance Core Principles - ICP), dispõe em 17.1.4:

Technical provisions and regulatory capital requirements should be covered by adequate and appropriate assets, having regard to the nature and quality of those assets. To allow for the quality of assets, supervisors may consider applying restrictions or adjustments (such as quantitative limits, asset eligibility criteria or "prudential filters") where the risks inherent in certain asset classes are not adequately covered by the regulatory capital requirements. (IAIS, 2015)

Essas regras tratadas neste item 2.2.2 do artigo, referentes à Cobertura de Provisões Técnicas, equivale, sob a diretiva de Solvência II, à uma fração da primeira seção da coluna da esquerda da Figura 1 - Balanço sob Solvência II, sendo sua complementação consistida pelos Ativos Redutores da Necessidade de Cobertura - tratado a seguir.

\subsubsection{Ativos redutores da necessidade de cobertura das provisões técnicas}

A Resolução CNSP n. 277/13 alterou e consolidou o art. 13 da Resolução CNSP n. 226/10 com o objetivo de dispor sobre quais valores podem ser utilizados como redutores da necessidade de cobertura das provisões técnicas por ativos garantidores.

Posteriormente, a Resolução CNSP n. 321/15 as consolidou e, atualmente, é o principal dispositivo regulatório sobre o tema. De acordo com essa Resolução e regulamentação constante na Circular Susep n. 517/2015, as seguradoras podem oferecer como redutores da necessidade de cobertura das provisões técnicas por ativos garantidores: Direitos Creditórios, Ativos de Resseguro Redutores, Depósito Judiciais Redutores e Custo de Aquisição Diferidos Redutores.

A seguir, apresentaremos breve descrição desses ativos que são aceitos como redutores da necessidade de cobertura das provisóes técnicas (passaremos a chamar apenas como Ativos Redutores):

\section{(Markowitz, 1952)}

8 A publicação dos princípios da IAIS pode ser encontrada em www.iaisweb.org. 
i. Direitos creditórios.

(1) Os valores de direitos creditórios correspondem ao montante de prêmios a receber, referente às parcelas não vencidas, na proporção dos prazos dos riscos a decorrer.

ii. Ativos de resseguro redutores.

(1) o valor dos prêmios de resseguro diferidos diretamente relacionados às provisões técnicas da cedente, líquidos de montantes pendentes de pagamento à contraparte.

(2) o valor esperado dos fluxos de caixa de sinistros e benefícios ocorridos e ainda não pagos pela cedente, decorrentes do cumprimento dos contratos de resseguro.

(3) o valor da parcela da insuficiência das provisões técnicas, apurada no TAP, de responsabilidade dos resseguradores.

iii. Depósitos judiciais redutores.

(1) parcelas dos depósitos judiciais relacionadas às provisões técnicas, limitado o montante do sinistro pendente de liquidação correspondente, líquido do ativo de resseguro ou retrocessão redutor.

iv. Custos de aquisição diferidos redutores.

(1) os custos de aquisição diferidos referentes às despesas de corretagem, efetivamente liquidadas, diretamente relacionadas ao valor do prêmio comercial e diferidas de acordo com a vigência de cada risco.

Vale notar que os Ativos Redutores são Ativos diretamente relacionados com a provisão a que se referem, conforme exemplificado a seguir:

Direitos Creditórios: - Referência: PPNG-RVE e PPNG-RVNE

Independentemente se o risco foi emitido ou não, os Direitos Creditórios corresponderão aos Prêmios a Receber referentes ao risco a decorrer, desde que não estejam vencidos. Lembrando que a PPNG é constituída, justamente, pela parcela de prêmios a decorrer, concluímos que existe um relacionamento perfeito entre os Direitos Creditórios que podem ser oferecidos como Ativo Redutor e a PPNG. A diferença entre os Direitos Creditórios referentes a PPNG-RVE e PPNG-RVNE consiste em que os primeiros são calculados a partir de uma metodologia padrão, enquanto os segundos, cálculos atuariais. 
-• Economia Brasileira em Debate

Ativos de Resseguro

Redutores - Prêmios: - Referência: PPNG-RVE e PPNG-RVNE

O Ativos de Resseguro Redutores corresponderão aos Prêmios liquidados junto aos Resseguradores referentes ao risco a decorrer. Lembrando, novamente, que a PPNG é constituída pela parcela de prêmios a decorrer, concluímos que existe um relacionamento perfeito entre os Ativos de Resseguro Redutores e a PPNG.

De forma geral, o ativo de resseguro redutor de PPNG-RVNE será nulo. Na maioria dos casos, a companhia somente paga a parcela do prêmio cedido ao ressegurador após a emissão a apólice, e, portanto, os ativos de resseguro de PPNG-RVNE não poderão ser oferecidos como redutores da necessidade de cobertura das provisões técnicas.

\section{Ativos de Resseguro}

Redutores - Sinistros: - Referência: PSL

O Ativos de Resseguro Redutores corresponderão as indenizaçôes a liquidar de sinistros avisados (ou seja, estão contabilizados na PSL) e ainda não recuperadas do Ressegurador.

Vale notar que, caso a Seguradora já tenha liquidado o sinistro, o valor a recuperar não poderá ser utilizado como Ativo Redutor, justamente por não ter uma correspondência com as Provisões Técnicas.

Ativos de Resseguro

\section{Redutores- Sinistros: - Referência: IBNR}

Como não há pagamento de sinistro antes do aviso, todo o valor estimado de sinistro a recuperar do ressegurador, relativo aos sinistros ocorridos e não avisados, poderá, de forma geral, ser considerado como ativo de resseguro redutor de IBNR.

Existem outros Ativos Redutores (Depósitos Judiciais e Custo de Aquisição Diferidos), bem como referência a outras provisões" (exemplo: PDR, PMBAC, PMBC, PDR e PCC), sendo que, invariavelmente, serão observadas a preocupação com a qualidade do ativo (tal qual nos Direitos Creditórios quando, ainda que estejam a decorrer, os prêmios não podem estar vencidos para que sejam aceito) e a relação direta entre o Ativo e a Provisão a qual a necessidade de cobertura está sendo reduzida, sendo que, não pode haver duplicidade de valores oferecidos como redutores da necessidade de cobertura das provisões técnicas por ativos garantidores.

Os diferentes valores redutores deverão ser considerados líquidos uns dos outros e a sua soma não pode exceder o valor da provisão correspondente. Ou seja,

9 Informações mais detalhadas podem ser encontradas em (Susep, 2017c) encontrado no site www.susep.gov.br 
custos de aquisição diferidos redutores, direitos creditórios e ativos de resseguro redutores podem ser utilizados concomitantemente desde que se refiram a diferentes parcelas do prêmio, assim como depósitos judiciais e ativos de resseguro redutores podem ser utilizados concomitantemente desde que se refiram a diferentes parcelas do sinistro.

Assim, podemos afirmar que as Normas que tratam sobre os Ativos Redutores encontram-se alinhadas as Normas Internacionais, em especial, o Princípio 17.1.4 do ICP - 17, transcrito no item 2.2.2 - Ativos Garantidores de Provisão Técnica, acerca das características mínimas do ativo para fins de aceitação pelo órgão regulador.

\section{Capital Mínimo Requerido (CMR)}

Em $1^{\circ}$ de janeiro de 2014, início de vigência da Resolução CNSP n. 302/2013, foi revogada uma antiga regra, denotada Margem de Solvência, que considera apenas o maior valor entre $20 \%$ do total de prêmios emitidos nos últimos doze meses e $33 \%$ da média anual do total de sinistro retidos dos últimos trinta e seis meses (CNSP, 2001).

Assim, a Margem de Solvência, não considerava os Riscos a que as Seguradoras estão sujeitas e, portanto, tal regra não é alinhada aos Normativos Internacionais, incluindo as diretivas de Solvência II. De acordo com Solvência II, em Cálculo do Capital de solvência Requerido, temos:

The Solvency Capital Requirement shall cover at least the following risks:
(a) non-lifeunderwritingrisk.
(b) lifeunderwritingrisk.
(c) healthunderwritingrisk.
(d) marketrisk.
(e) creditrisk.
(f) operationalrisk.

É importante notar que, apesar dessa regra ter vigorado até 2014, desde $1^{\circ} \mathrm{de}$ janeiro de $2008^{10}$, seguindo o processo de alinhamento às regras internacionais, entrou em vigência o primeiro Normativo acerca dos Capitais de Risco, especificamente, Capital Adicional para Risco de Subscrição.

10 Início de vigência de vigência da Resolução CNSP 155/2006. 
Atualmente, através da Resolução CNSP n. 321/2015 e Circular Susep n. $517 / 2015$, temos completa a regulação de quatro Capitais de Risco, sendo esses definidos como o montante variável de capital que a Seguradora deverá manter, a qualquer tempo, para garantir:

- Riscos de subscrição: Possibilidade de ocorrência de perdas que contrariem as expectativas da supervisionada, associadas, diretamente ou indiretamente, às bases técnicas utilizadas para cálculo de prêmios, contribuições, quotas e provisões técnicas.

- Riscos de crédito: Possibilidade de ocorrência de perdas associadas ao não cumprimento, pelo tomador ou contraparte, das suas respectivas obrigações financeiras nos termos pactuados, e/ou da desvalorização dos recebíveis decorrente da redução na classificação de risco do tomador ou contraparte.

- $\quad$ Riscos de operacional: possibilidade de ocorrência de perdas resultantes de falha, deficiência ou inadequação de processos internos, pessoas e sistemas, ou decorrentes de fraudes ou eventos externos, incluindo-se o risco lega ${ }^{11}$ e excluindo-se os riscos decorrentes de decisóes estratégicas e à reputação da instituiçãa.

- $\quad$ Riscos de mercado: possibilidade de ocorrência de perdas resultantes de flutuações dos mercados financeiros, que causam mudanças na avaliação econômica de ativos e passivos das supervisionadas.

Na Resolução CNSP n. 321/2015 encontramos as fórmulas padrões para o Cálculo de Capital voltado para cada um desses riscos acima listados. O Capital de Risco - CR - (definido como o montante variável de capital que a Seguradora, deverá manter a qualquer tempo, para garantir os riscos inerente à operação) não é, em virtude da correlação, o simples somatório dos quatro Capitais de Riscos, mas segue fórmula ${ }^{12}$ padrão abaixo, que considera apenas o Risco Operacional Independente:

\footnotetext{
11 Risco Legal: possibilidade de ocorrência de perdas decorrentes de multas, penalidades ou indenizações resultantes de ações de órgãos de supervisão e controle, bem como perdas decorrentes de decisão desfavorável em processos judiciais ou administrativos.

12 Anexo XXVI da Resolução n. 321/2015.
} 
Equação 1 - Capital de Risco

$C R=C R_{O P E R}+\sqrt{\sum_{i} \sum_{j} \rho_{i j} X C R_{i} X C R_{j}}$

CR - capital de risco

CRi e $\mathbf{C R j}$ - parcelas do capital baseadas nos riscos “i” e "j", respectivamente, sendo:

I - CRsubs - parcela do capital de risco de subscrição

II - CRcred - parcela do capital de risco de crédito

III - CRmerc - parcela do capital de risco de mercado

CRoper - parcela do capital de risco operacional, definido nesta

$\rho_{i j}$ - elemento da linha "i" e coluna "j" da matriz de correlação constante na Resolução.

É importante ressaltar que, também alinhado pelas Normas Internacionais, as Seguradoras passaram a contar com a faculdade de encaminhar metodologia própria para apuração das parcelas de risco, desde que observados alguns requisitos mínimos $^{13}$. Esse dispositivo é tratado no ICP 17, conforme transcrito a seguir:

By its very nature a standardised approach may not be able tofully and appropriately reflect the risk profile of each individual insurer. Therefore, where appropriate, a supervisor should allow the use of more tailored approaches subject to approval. In particular, where an insurer has an internal model (or partial internal model) that appropriately reflects its risks and disintegrated into its risk management and reporting, the supervisor should allow the use of such a model to determine more tailored regulatory capital requirements, where appropriate. The use of the internal model for this purpose would be subject to prior approval by the supervisor based on a transparent set of criteria and would need to be evaluated at regular intervals. In particular, the supervisor would need to be satisfied that he insurer'si nternal model is, and remains, appropriately calibrated relative to the target criteria established by the supervisor

A Resolução CNSP n. 321/2015 prevê, ainda, outro dispositivo:

Capital Base. O Capital Base é uma barreira a entrada e, para operação em seguros, é obtido pelo somatório da parcela fixa correspondente à autorização $(\mathrm{R} \$$ 1,2 milhões) e parcela variável determinada de acordo com a região em que a seguradora tem autorização para operar ( $\mathrm{R}$ \$ 120.000,00 a $\mathrm{R}$ \$ 13,8 milhões) e, portanto, o seu valor máximo é de 15 milhões.

13 Ver art. 20 do anexo XXVI da Resolução CNSP 321/2015 
-• Economia Brasileira em Debate

O Capital Mínimo Requerido (CMR) é o máximo entre o Capital Base (que varia de 1,2 a 15 milhões de Reais) e o Capital de Risco (determinado segundo a Equação 1).

\section{O Patrimônio Líquido Ajustado e o CMR}

$\mathrm{O}$ art. 66 da Resolução CNSP n. 321/2015 dispõe que as seguradoras deverão apresentar mensalmente, quando do fechamento dos balancetes mensais, Patrimônio Liquido Ajustado (PLA) igual ou superior ao Capital Minimo Requerido (CMR) e liquidez em relação ao Capital de Risco (CR).

Depreende-se, então, que o primeiro dispositivo para apuração da Solvência de uma Seguradora é a verificação do CMR com relação ao PLA. O PLA é calculado com base no patrimônio líquido contábil, processadas deduções previstas em $\mathrm{Norma}^{14}$.

Importante notar que na hipótese de insuficiência de PLA em relação ao CMR de até 50\% (cinquenta por cento) ou de insuficiência de liquidez em relação ao CR, a seguradora deverá apresentar Plano de Recuperação de Solvência, na forma disposta no Normativo, propondo plano de ação que vise à recomposição da situação de solvência, enquanto estarão sujeitas ao regime especial de direção-fis$\mathrm{cal}^{15}$, quando a insuficiência de PLA, em relação ao CMR, for maior que 50\% (cinquenta por cento) e menor ou igual a $70 \%$ (setenta por cento). No caso de a insuficiência superar 70\% a Seguradora fica sujeita a Liquidação Extrajudicial.

Nota-se que essa gradação (Solicitação de Plano de Recuperação de Solvência, Direção Fiscal, Liquidação), está alinhada com o demonstrado na Figura 1 - Balanço sob Solvência II e com o ICP 17, que determina dois níveis (PCR e $M C R$ ), sendo o MCR o nivel em que o regulador deve tomar as açôes mais severas, conforme transcrição a seguir:

In the context of insurance legal entity capital adequacy assessment, the regulatory capital requirements establish:

- A solvency control level above which the supervisor does not intervene on capital adequacy grounds. Thisis referred to as the Prescribed Capital Requirement (PCR). The PCR is defined such that assets will exceed technical provisions and other liabilities with a specified level of safety over a defined time horizon.

14 As deduções estão previstas no Art. 64 da Resolução CNSP n. 321/2015 e englobam ativos como despesas antecipadas não relacionadas a resseguro, ativos intangíveis, obras de arte e pedras preciosas.

15 O Regime de Direção Fiscal é o primeiro grau de intervenção realizado pela Susep. 
- A solvency control level at which, if breached, the supervisor would invoke its strongest actions, in the absence of appropriate corrective action by the insurance legal entity. This is referred to as theMinimum Capital Requirement (MCR). The MCR is subject to a minimum bound below which no insurer is regarded to be viable to operate effectively

Assim, com relação às deduções do Patrimônio Líquido para obtenção do PLA, verifica-se que as diretivas de Solvência II designam ao regulador a determinação dos ativos que serão aceitos para fins de solvência.

\section{Liquidez em Relação ao Capital de Risco e Margem de Segurança das Provisões Técnicas}

Segundo as diretivas de Solvência II, as Seguradoras devem calcular uma Margem de Risco das Provisões Técnicas em excesso a melhor estimativa (ver Figura 1 - Balanço sob Solvência II). A Susep (Susep, 2017d) entende que conceito de provisões técnicas se fundamenta, de forma geral, no valor esperado das obrigações a pagar, que os montantes que excedem os valores esperados das obrigações são abrangidas pelos capitais de risco e que estimativas que incorporem volatilidade não são adequados para calcular provisões técnicas.

Apesar da posição contundente da Superintendência, existe o dispositivo liquidez em relação ao Capital de Risco no arcabouço regulatório, que é a situação caracterizada quando a supervisionada apresenta montante de ativos líquidos, em excesso à necessidade de cobertura das provisóes técnicas, superior a 20\% (vinte por cento) do CR, deduzido deste o valor do superávit de fluxos de prêmios/contribuições não registrados apurado no TAP, limitado ao efeito no CR da parcela de risco de mercado relativa aos fluxos de prêmios e contribuiçôes não registradas.

Importante notar que os ativos líquidos são os ativos aceitos pelo Conselho Monetário Nacional na cobertura das provisões técnicas, assim, ainda que no arcabouço regulatório brasileiro não exista a margem de segurança para provisões técnicas, existe a exigência de um montante em excesso a cobertura das provisões.

A exigência de liquidez com relação ao CR não se confunde com a Margem de Segurança, afinal, a primeira, diferentemente da segunda, não sensibiliza o Capital Social. Por outro lado, acaba a liquidez com relação ao CR cumprindo papel semelhante, pois, em uma situação de readequação das Provisões Técnicas (por exemplo em virtude do Resultado positivo do LAT), a Seguradora, dentro dos limites da 
-• Economia Brasileira em Debate

liquidez com relação ao $\mathrm{CR}$, não estará exposta ao risco de não cobertura das Provisões Técnicas (situação grave e que não possui dispositivos de gradação), mas apenas, se estiver com o PLA próximo ao CMR, de Insolvência com relação ao Capital (situação que, em função das gradações apresentadas anteriormente, menos gravosa).

Síntese das Normas Brasileiras sob o Pilar I de Solvência II

Com base no exposto anteriormente, há nas Normas Brasileiras:

1) Provisões Técnicas

2) Cobertura das Provisões Técnicas

a. Ativos Líquidos

b. Ativos Redutores

3) Liquidez com relação ao $\mathrm{CR}$

4) Capital Mínimo Requerido

a. Plano de Recuperação de Solvência

b. Direção Fiscal

c. Liquidação Extrajudicial

Para fins de comparação, desenvolveremos figura semelhante a Figura 1 - Balanço sob Solvência II:

Figura 2 Balanço sob Normas Brasileiras.

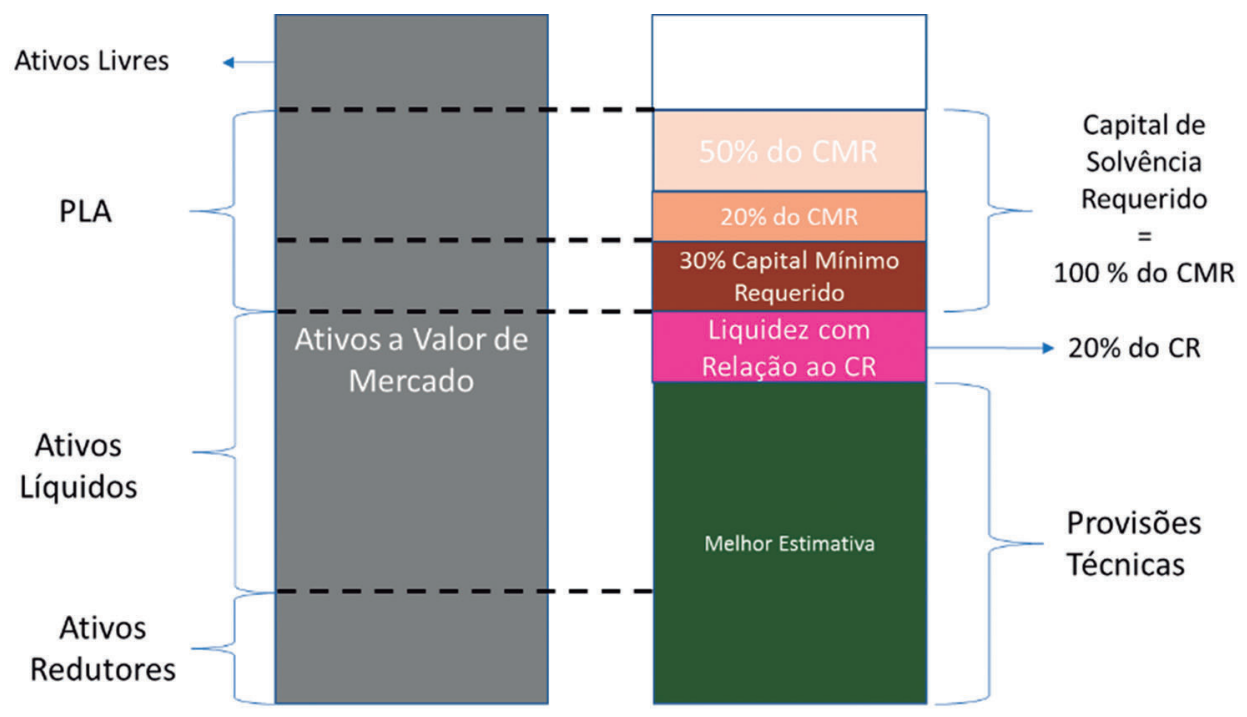




\section{PILAR II - PROCEDIMENTOS DE SUPERVISÃO}

De acordo com as diretivas de Basileia II, o processo de revisão do regulador não deve se limitar à verificação da adequação das Seguradoras às Normas de Capitais, mas também a boa governança e atendimento das Normas respectivas.

Para melhor ilustrar destacamos o que diz as Normas de Solvência II quanto ao processo de revisão do supervisor:

Member States shall ensure that the supervisory authorities review and evaluate the strategies, processes and reporting procedures which are established by the insurance and reinsurance under takings to comply with the laws, regulations and administrative provisions adopted pursuantto this Directive.

That review and evaluation shall comprise the assessment of the qualitative requirements relating to the system o fgovernance, the assessment of the risks which the undertakings concerned face or may face and the assessment of the ability of those undertakings to assess those risks taking into account the environment in which the undertakings are operating. (EUROPEAN PARLIAMENT AND THE COUNCIL OF THE EUROPEAN UNION, 2014)

Seguindo essa linha, a partir da publicação da Circular Susep 249 de 20 de fevereiro de 2004, acentuou-se a formação do arcabouço regulatório voltado para Gestão de Risco, que desde então se encontra em constante desenvolvimento. Dos Normativos, destacamos sobre Controles Internos:

- Circular Susep n. 249/2004: Dispõe sobre a implantação de sistemas de controles internos nas Seguradoras e ainda que a atividade de auditoria interna deve fazer parte do sistema de controles internos, acerca da independência da auditoria interna e atividades mínimas e sobre as atribuições do Diretor responsável pelos controles internos (obrigatoriamente, estatutário).

- Circular Susep n. 280/2004: Estabelece procedimentos mínimos a serem observados no relatório circunstanciado sobre a adequação dos controles internos e no relatório circunstanciado sobre o descumprimento de dispositivos legais e regulamentares, produzidos quando da auditoria das Seguradoras. Dispóe que o relatório circunstanciado sobre a adequação dos controles internos deverá avaliar a eficácia e a eficiência dos mesmos em relação aos riscos suportados, destacando as deficiências encontradas, levando em consideração os principais processos existentes na sociedade e abordando o ambiente de controle, a avaliação de riscos, as atividades e procedimentos de controles, os processos de 
informação e comunicação, e a monitoração. Com relação ao relatório circunstanciado sobre o descumprimento de dispositivos legais e regulamentares, prevê que deve avaliar situações que tenham, ou possam vir a ter, reflexos relevantes nas demonstrações contábeis ou na continuidade das operações da sociedade supervisionada auditada. Essa Circular foi revogada pela Circular Susep n. 517/2015, entretanto, seus dispositivos encontram-se nela recepcionados.

- Circular Susep n. 327/2006 e alterações: Dispóe sobre os Controles Internos específicos para o combate ao Crime de Lavagem de Dinheiro e que deverá ser indicado um diretor específico (estatutário). Essa Circular foi revogada pela Circular Susep n. 380/08, que por sua vez introduziu novas obrigações, bem como o conceito de Pessoa Politicamente Exposta. A Circular Susep n. 380/08 foi revogada pela Circular n. 445/2012 que também trouxe novos dispositivos.

- Circular Susep n. 344/2007 e alterações: Dispõe sobre os Controles Internos específicos para a prevenção de fraudes e que deverá ser indicado um diretor específico (estatutário).

- Circular Susep n. 484/2014 - Dispõe sobre a exigência de exame de certificação do auditor independente e sobre a educação profissional continuada do auditor independente. Revogada e recepcionada pela Circular Susep n. 517/2015.

- Circular Susep n. 521/2015 - Dispõe sobre a Estrutura da Gestão de Risco. Um salto significativamente importante no marco regulatório no alinhamento aos procedimentos internacionais. Prevê, entre outros dispositivos, que as Seguradoras deverão implantar Estruturas de Gestão de Risco, que deverá se alinhada com o Sistema de Controles Internos, que é de responsabilidade da Diretoria e do Conselho de administração o seu zelo, e, em especial, elaboração e manutenção de um Perfil de Risco, Apetite de Risco e a nomeação de um Gestor de Risco ou equivalente ${ }^{16}$. O prazo para implantação é dezembro de 2017.

Referindo-nos à importância da Circular Susep n. 521/2015 para o alinhamento às Normas Internacionais, destacamos a seguinte diretiva de Solvência II:

16 Informações mais detalhadas em (Susep, 2017a). 
Insurance and reinsurance undertakings shall have written policies in relation to at least risk management, interna lcontrol, internal audit and, where relevant, outsourcing. They shal lensure that those policies are implemented.

Those written policies shall be reviewed at least annually. They shall be subject to prior approval by the administrative, management or supervisory body and be adapted in view of any significant change in the system or are concerned. (EUROPEAN PARLIAMENT AND THE COUNCIL OF THE EUROPEAN UNION, 2014)

O segundo pilar de Solvência II também alcança o conhecimento do legislador do mercado regulado e, seguindo tal diretiva, há Normas publicadas com esse efeito:

- Circular Susep 253/2004 e alteraçóes: Com objetivo de conhecer os riscos os quais as Seguradoras estão sujeitas para, assim, regular os respectivos Capitais de Risco (em especial o de subscrição, cuja regulação ocorreu em 2006 ${ }^{17}$ ). Essa Circular foi revogada em 2016.

- Circular Susep n. 492/2014: Com efeitos para 2016/2017, dispõe sobre os critérios para a constituição de banco de dados de perdas operacionais pelas seguradoras, para fins de estudos de aprimoramento do modelo regulatório de capital de risco baseado no risco operacional. Conforme previsto nos princípios do IAIS (17.7.5 - 17.7.6), o risco operacional é de difícil mensuração e que a formação de uma base é recomendada:

The measurement of operational risk, in particular, may suffer from a lack of sufficiently uniform and robust data and well developed valuation methods.

(...) However, the IAIS envisages that the ability to quantify some risks (such as operational risk) will improve over time as more data become available or improved valuation methods and modelling approaches are developed. (IAIS, 2015)

Dentro ainda do Pilar II, podemos destacar outros dispositivos encontrados na legislaçãao ${ }^{18}$, tais como a obrigatoriedade de designar um Atuário Responsável, sobre as regras de definição do Limite de Retençãa ${ }^{19}$ de acordo com metodologia atuarial e a auditoria atuarial.

\section{PILAR III - DISCIPLINA DE MERCADO}

Constituído especialmente com vistas à Transparência, uma vez que, de acordo com os princípios do IAIS, o Pilar III inclui áreas tais quais que lidam com os

17 Resolução CNSP n. 155/2006.

18 Ver Resolução CNSP n. 321/2015 e na Circular Susep n. 253/2004.

19 Limite de retenção é o valor máximo de responsabilidade que as seguradoras, EAPC e resseguradores locais podem reter em cada risco isolado. 
consumidores na venda e no tratamento das apólices de seguro e abertura das informações relevantes tanto para o mercado quanto para os segurados, conforme constante no ICP 20:

The supervisor requires insurers to disclose relevant, comprehensive and adequate information on a timely basis in order to give policy holders and Market participants a clear view of their business activities, performance and financial position. This is expected to enhance market discipline and understanding of the risks to which an insurer is exposed and the manner in which those risks are managed. (IAIS, 2015)

Referindo-nos à apresentação das Contas Contábeis, a partir da Resolução CNSP n. 195/2008, as Provisóes Técnicas passaram a ser apresentadas brutas de Resseguro no Passivo, enquanto direitos das Seguradoras junto ao Ressegurador, no Ativo, alinhando-se a um Princípio Básico das Normas Internacionais, tal como disposto no item 20.2.1 do ICP - 20 - Divulgação Pública.

Presentation of technical provisions and reinsurance assets on a gross basisis expected. However, it may be use ful to presente information abou technical provisionson both a net and gross basis depending on typical measures of performance and solvency that are applied by market participants. (IAIS, 2015)

Não obstante, os elementos mínimos que devem ser apresentados por força dos Normativos as Notas Explicativas mostram abrangência significativa, uma vez que o art. 157 da Circular n. 517/2015 dispõe que deverão ser divulgadas em notas explicativas todas as informações previstas por cada pronunciamento contábil aprovado pelo CPC. Os estudos de impacto do IFRS 4 demonstram que a adoção dessas Normas pela primeira vez provoca um aumento médio de 150\% no volume das informações contábeis ${ }^{20}$.

Por sua vez, a Susep disponibiliza em seu site as demonstrações financeiras (anuais e intermediárias), situação de adequação da Seguradora e da respectiva diretoria junto ao órgão (certidão de regularidade), e produtos comercializados, entretanto, ao contrário das Seguradoras que se encontram em regime especial, não há uma listagem das que estão em cumprimento de Plano de Regularização de Solvência ${ }^{21}$.

\section{EFETIVIDADE DAS NORMAS DE SOLVÊNCIA}

O Brasil está enfrentando a mais longa crise de sua história e sua gravidade pode ser explicitada através dos seguintes pontos:

\footnotetext{
20 Ver (Paraskevopoulos \& Mourad, 2009, pp. 1-4)

21 Ver (Susep, 2017f)
} 
1) O Brasil tem enfrentado quedas do Produto Interno Bruto (PIB) desde o segundo trimestre de 2014.

2) A materialização do risco de crédito a empresas tem sido desafiadora para a estabilidade financeira no período recente. A queda do crescimento da carteira aprofundou-se com o declínio da atividade econômica, as altas taxas de juros e a maior seletividade por parte das instituições financeiras.

3) $\mathrm{O}$ ambiente corporativo em 2016 repercutiu em piora no emprego

4) Queda da arrecadação, com reflexos nos entes subnacionais

a) Essa queda tem colocado desafios para vários entes subnacionais. Exemplo disso é a relação divulgada pela Secretaria do Tesouro Nacional (STN) que classifica um conjunto de estados e municípios como em situação financeira "fraca" ou pior.

\begin{tabular}{|c|c|c|c|c|c|c|}
\hline \multirow[b]{2}{*}{ Grupo } & \multirow[b]{2}{*}{ Capag } & \multirow[b]{2}{*}{ Estados } & \multirow[b]{2}{*}{ Municípios } & \multicolumn{2}{|c|}{ Exposição em R\$ bilhão' } & \multirow[b]{2}{*}{$\%$ Total } \\
\hline & & & & Estados & Municípios & \\
\hline \multirow{2}{*}{ Desequilibrio Fiscal } & D & MG, RJ, RS & & 32,2 & - & \multirow{2}{*}{$33 \%$} \\
\hline & D+ & GO & & 9,4 & - & \\
\hline \multirow{2}{*}{$\begin{array}{r}\text { Situação fiscal muito fraca / risco } \\
\text { de crédito muito alto }\end{array}$} & C- & AL, MS, SP & Itabuna-BA & 17,6 & 0,0 & \multirow{2}{*}{$20 \%$} \\
\hline & C & $\mathrm{AC}, \mathrm{SC}$ & & 7,7 & - & \\
\hline $\begin{array}{r}\text { Situação fiscal fraca } / \text { risco de } \\
\text { crédito relevante }\end{array}$ & $\mathrm{C}+$ & $\begin{array}{l}\text { PB, PI, RN, } \\
\text { SE }\end{array}$ & $\begin{array}{l}\text { Arapiraca/AL, Americana/SP, } \\
\text { Sumaré/SP, São Paulo/SP, } \\
\text { Campina Grande/PB, Porto } \\
\text { Velho/RO }\end{array}$ & 5,4 & 0,3 & $4 \%$ \\
\hline $\begin{array}{l}\text { Situação fiscal boa / } \\
\text { risco de crédito médio }\end{array}$ & B- & $\begin{array}{l}\text { AM, AP, BA, } \\
\text { CE, DF, MA, } \\
\text { MT, PE, PR, } \\
\text { RO, TO }\end{array}$ & 25 municípios & 26,6 & \multirow{5}{*}{22,4} & \multirow{5}{*}{$43 \%$} \\
\hline \multirow{2}{*}{$\begin{array}{l}\text { Situação fiscal forte } / \\
\text { risco de crédito baixo }\end{array}$} & B & ES, RR & 42 municípios & 4,2 & & \\
\hline & $B+$ & PA & 23 municípios & 1,5 & & \\
\hline $\begin{array}{r}\text { Situação fiscal muito forte } \\
\text { ou excelente / } \\
\text { risco crédito muito baixo ou } \\
\text { quase nulo } \\
\end{array}$ & $\begin{array}{c}\mathrm{A}-\mid \mathrm{A} / \\
\mathrm{A}+\end{array}$ & Nenhum & 25 municípios & - & & \\
\hline Sem nota de cré dito & NR & Nenhum & 5.448 municípios & - & & \\
\hline \multicolumn{3}{|l|}{ Total } & 5.570 municipios & 104,5 & 22,7 & $100 \%$ \\
\hline
\end{tabular}

'Exposição bruta de Crédito. Não inclui empres as públicas.

5) As propostas políticas e econômicas e as promessas de campanha feitas pelo novo presidente americano tornaram a mudança de governo nos Estados Unidos da América (EUA) um evento de impacto global, que merece acompanhamento pela existência de alguns riscos: 
-• Economia Brasileira em Debate

6) Os Fatores externos não têm provocado consequências relevantes para a estabilidade financeira no Brasil, mas o ambiente permanece incerto e demanda atenção.

7) O Brasil sofreu a retirada de grau de investimento, que havia conseguido manter por 7 anos.

Apesar do cenário adverso, em (Bacen, 2017), encontramos que no curto prazo, o estoque de crédito deve continuar em declínio, e os ativos problemáticos, em ascensão. O sistema bancário tem demonstrado estar preparado para lidar com esse cenário complexo e para se ajustar a eventual aumento de risco.

Por sua vez, também não encontramos sinais de risco sistêmico no mercado segurador, uma vez que, analisando as Seguradoras que se encontram em Regime Especial, nenhuma Seguradora se encontra em Direção Fiscal (conforme exposto no item 2.2.5 - O Patrimônio Líquido Ajustado e o CMR trata-se do grau de intervenção posteriores ao Plano de Recuperação de Solvência) e, nos últimos cinco anos, foram decretadas as Liquidações de quatro seguradoras, sendo que, uma delas não mais operava e a participação das outras três, como base no exercício de 2011, não alcançava 1\% dos Prêmios de Seguros (Susep, 2017f).

Não é possível afirmar que se, tanto o setor financeiro regulado pelo Bacen, quanto as Seguradoras, reguladas pela Susep, não estivessem sob uma regulação cujas principais diretrizes são Basileia II e Solvência II, respectivamente, já encontraríamos nesses setores as ocorrências decorrentes do Risco Sistêmico, entretanto, podemos categoricamente afirmar que, frente a gravidade da crise que o país está imergido, as novas regras trouxeram segurança ao setor.

Por outro lado, conforme também aconteceu no mercado externo, está ocorrendo uma concentração no mercado de seguros, conforme extraído do $4^{\circ}$ Relatório De Análise e Acompanhamento dos Mercados Supervisionados, de julho de $2016^{22}$ :

22 (Susep, 2016a). 
Figura 3 Concentração por Empresa.
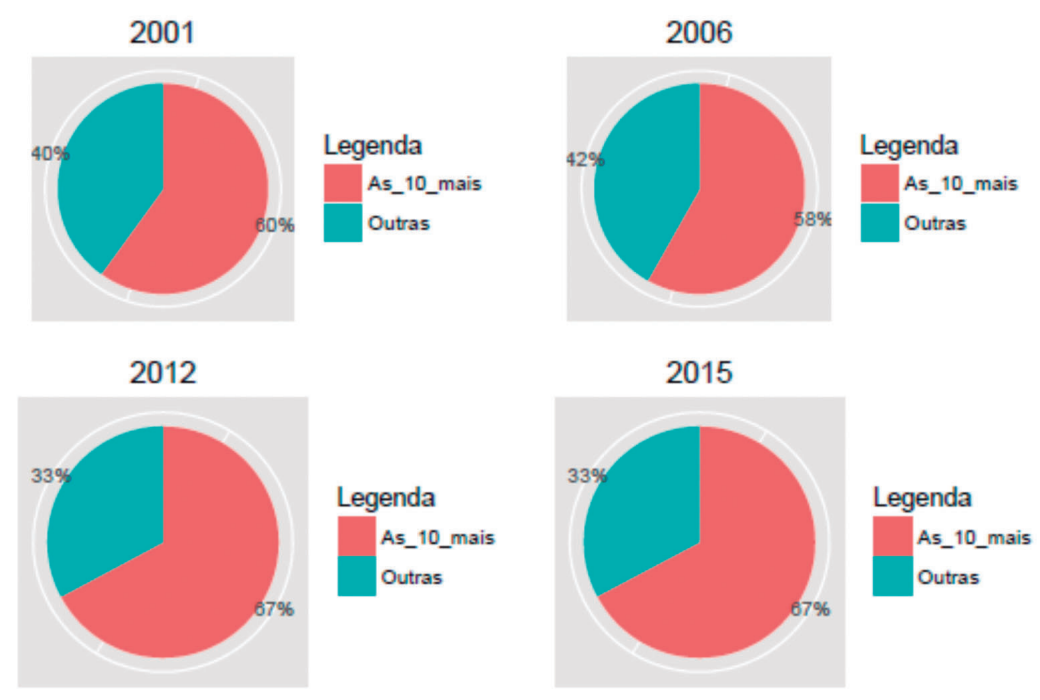

De acordo o relatório "a análise desses gráficos indica a tendência a uma maior concentração, o que não surpreende, tendo em vista os inúmeros processos de fusão e incorporação de empresas ocorridos entre 2006 e 2012". Vale ressaltar que esse período, conforme exposto anteriormente, compreende o marco regulatório de início de implantação das diretivas de Solvência II.

\section{CONSIDERAÇÕES FINAIS}

O processo de implantação das diretivas de Solvência II no Brasil alcança os três pilares, substituindo o modelo que levava em consideração apenas os Requerimentos de Capital e adota um que considera todos os riscos os quais as Seguradoras estão expostas. Assim, tornando essencial a Gestão de Riscos (Pilar II) e o fornecimento de informações para o mercado como um todo (Pilar III).

Os Requerimentos de Capital (Pilar I), por sua vez, sofreram significativo desenvolvimento desde 2006 com a regulamentação do Capital Adicional para Risco de Subscrição até a conclusão da regulamentação do Capital de Risco e maior aderência às principais Normas e aos princípios do IAIS.

Por fim, demonstramos que o cenário econômico brasileiro é bastante adverso, mas que o Mercado Financeiro e de Seguros se mostra solvente, entretanto, o de seguros, vem apresentando processo de concentração. 
-• Economia Brasileira em Debate

\section{REFERÊNCIAS}

Bacen. (2017). Relatório de Estabilidade Financeira, v. 16, n. 1, abril 2017. Brasília.

BIS. (1999). A New Capital Adequacy Framework. Basel Committee on Banking Supervision, Basileia - Suíça.

CNSP. (2013). Resolução CNSP 281, 2013. Rio de Janeiro.

CNSP. (2016). Resolução CNSP n. 321, de 2015, compilada 2016. Rio de Janeiro.

CNSP. (2009). Resolução CNSP n. 162, de 2006, consolidado em 2009. Rio de Janeiro.

CNSP. (2010). Resolução CNSP n. 195, 2008, consolidada em 2010. Rio de Janeiro.

CNSP. (2001). Resolução CNSP n. 55, 2001. Rio de Janeiro.

Conselho Monetário Nacional. (2017). Resolução n. 4.444, de 13 de novembro de 2015, consolidada em 26 de abril de 2017.

EUROPEAN PARLIAMENT AND THE COUNCIL OF THE EUROPEAN UNION. (2014). DIRECTIVE 2009/138/EC OF THE EUROPEAN PARLIAMENT AND OF THE COUNCIL (recast).

IAIS. (2015). Insurance Core Principles.

International Accounting Standards Board (IASB). (2009). International Financial Reporting Standard 4.

Markowitz, M. H. (March de 1952). Portfolio Selection. Journal of Finance 7, p. 77-91.

Melo, E. F., \& Neves, C. d. (2012). Solvência no Mercado de Seguros e Previdência (1ª ed.). Rio de Janeiro: Escola Nacional de Seguros - FUNENSEG.

Paraskevopoulos, A., \& Mourad, N. A. (2009). IFRS 4 - Introdução à Contabilidade Internacional de Seguros. São Paulo: Saraiva.

Sandström, A. (2006). Solvency - Models, Assesment and Regulation ( $1^{\text {a }}$ ed.). Boca Raton, fl, EUA: Chapman \& Hall.

Susep. (2017f). Acesso em: 27/04/2017 de abril de 2017. Disponível em: www.susep. gov.br.

Susep. (2016a). 4o Relatório de Análise e Acompanhamento dos Mercados Supervisionados. Rio de Janeiro.

Susep. (2012a). Capital Adicional Relativo ao Risco Operacional. Susep, Rio de Janeiro.

Susep. (2017e). Cartilha de Investimentos - Orientaçôes da Susep ao Mercado. Rio de Janeiro.

Susep. (2007a). Circular SUSEP n. 253, de 12 de maio de 2004, consolidada em 2007. Rio de Janeiro.

Susep. (2014a). Circular SUSEP n. 249, de 20 de fevereiro de 2004, consolidada em 2014. Rio de Janeiro. 
A aderência das normas do mercado de seguros à diretiva de solvência Il e sua efetividade

Susep. (2004). Circular SUSEP n. 280, de 30 de dezembro de 2004. Rio de Janeiro.

Susep. (2007b). Circular SUSEP n. 327, de 29 de maio de 2006, consolidada em 2007. Rio de Janeiro.

Susep. (2008). Circular SUSEP n. 380, de 29 de dezembro de 2008. Rio de Janeiro.

Susep. (2012b). Circular SUSEP n. 410, de 22 de dezembro de 2010, consolidada em 2012. Rio de Janeiro.

Susep. (2014b). Circular SUSEP n. 457, de 14 de dezembro de 2012, consolidada em 2014. Rio de Janeiro.

Susep. (2014c). Circular SUSEP n. 484, de 6 de janeiro de 2014. Rio de Janeiro.

Susep. (2016b). Circular SUSEP n. 517, de 30 de julho de 2015, consolidada em 2016. Rio de Janeiro.

Susep. (2017a). Estrutura de Gestão de Riscos - Orientações da Susep ao Mercado - Versão 1.0. Rio de Janeiro.

Susep. (2017d). Provisōes Técnica - Orientaçōes da Susep ao Mercado. Rio de Janeiro.

Susep. (2017b). Teste de Adequação de Passivos - Orientaçôes da Susep ao Mercado - fevereiro de 2017. Rio de Janeiro.

Susep. (2017c). Valores Redutores da Necessidade de Cobertura das Provisöes Técnicas por Ativos Garantidores - Orientaçôes da Susep ao Mercado. 
